\title{
Intracranial Tumor Hemorrhage
}

National Cancer Institute

\section{Source}

National Cancer Institute. Intracranial Tumor Hemorrhage. NCI Thesaurus. Code C8619.

A brain hemorrhage caused by an intracranial tumor. 